\title{
Degradation of glyphosate in water, mineral surface, and soil
}

\author{
HUI LI ${ }^{1}$, MINGJING SUN ${ }^{2}$, ADAM WALLACE ${ }^{3}$, SPENCER \\ MOLLER $^{3}$ AND DEB P JAISI ${ }^{3}$
}

${ }^{1}$ Oak Ridge National Laboratory

${ }^{2}$ Emporia University

${ }^{3}$ University of Delaware

Presenting Author: jaisi@udel.edu

Glyphosate, the most commonly used herbicide in the world, can follow more than one degradation pathways and generate more toxic and persistent products such as aminomethylphosphonic acid (AMPA). Here we compared controlled laboratory studies on the degradation of glyphosate in water, mineral-water interface, and in soils in terms of the degradation pathways. The preference of $\mathrm{C}-\mathrm{P}$ or $\mathrm{C}-\mathrm{N}$ bond cleavage in glyphosate was found to vary with changing glyphosate/manganese oxide ratios, indicating the switchover of the AMPA and glycine pathway of degradation. The molecular simulation using DFT calculation showed that the $\mathrm{C}-\mathrm{P}$ bond could be cleaved by water, $\mathrm{OH}^{-}$, or $\cdot \mathrm{OH}$. In the presence of $\mathrm{Fe}$ and $\mathrm{Mn}$ oxide, competition between sorption and degradation was apparent: at a $\mathrm{Mn} / \mathrm{Fe}$ molar ratio of $<0.017$, sorptive removal of glyphosate dominated. In soils, degradation preferred towards the formation of AMPA. The ${ }^{18} \mathrm{O}$ labeling studies revealed that the fraction of inorganic $\mathrm{P}$ derived from glyphosate was rapidly recycled by soil microorganisms. These results collectively suggest that abiotic degradation preferentially follows the lesstoxic product pathways than biotic (soil) degradation. 